\title{
Medium term effects of a ketogenic diet and a Mediterranean diet on resting energy expenditure and respiratory ratio
}

\author{
Antonio Paoli ${ }^{1 *}$, Keith Grimaldi ${ }^{2}$, Antonino Bianco ${ }^{3}$, Alessandra Lodi ${ }^{4}$, Lorenzo Cenci ${ }^{5}$, Andrea Parmagnani ${ }^{1}$ \\ From Metabolism, diet and disease \\ Washington, DC, USA. 29-31 May 2012
}

\section{Background}

Very low carbohydrate ketogenic type diets (VLCKD) have been shown to be more effective for body weight reduction and fat loss compared to balanced or low-calorie Mediterranean diets, at least in the short-medium term $[1,2]$, although the underlying mechanisms of its efficacy are still not well understood. Despite being a diet in widespread use there are few data available regarding effects on respiratory ratio (RR) $[3,4]$ and resting energy expenditure (REE) and, more specifically, there are no reports about the effects on RR following a return to a non ketogenic diet. The aim of this study was to compare the effects of a 20 day ketogenic Mediterranean diet with phytoextracts (KEMEPHY) and a low-calorie Mediterranean diet (MD) on RR and REE during and 20 days after finishing the ketogenic phase.

\section{Materials and methods}

Forty healthy, overweight subjects were recruited and randomly divided into two groups: MD (age $46.61 \pm 14.6$, BMI $26.8 \pm 2.6$, weight $76.3 \pm 9.9 \mathrm{~kg}$ ) and KEMEPHY (age $50.63 \pm 11.6$, BMI $28.8 \pm 2.8$, weight $81.8 \pm 11.6 \mathrm{~kg})$. KEMEPHY group followed a ketogenic diet $(<30 \mathrm{~g} /$ day of carbohydrates) using meals that mimic the aspect and the taste of carbohydrates but with virtually zero $\mathrm{CHO}$ and with phytoextracts (Tisanoreica ${ }^{\circledR}$, Lonigo, Italy); after 20 days of strictly KD subjects followed a low carbohydrate non ketogenic diet for 20 days. The MD group followed a standard low-calorie Mediterranean diet (tot Kcal). REE and RR, together with body weight and body composition, were measured in the morning after overnight fasting at the start of the study and after $20\left(t_{20}\right)$ and 40 days $\left(t_{40}\right)$. An

${ }^{1}$ Biomedical Engineering Laboratory, Institute of Communication and Computer Systems, National Technical University of Athens, Athens, Greece Full list of author information is available at the end of the article
Anova test for repeated measures and unpaired t-test with Welch's correction were performed when appropriate.

\section{Results}

Compared to starting values $R R$ was significantly decreased in the KEMEPHY group after 20 days $(\mathrm{p}<0.05)$ and after 40 days $(\mathrm{p}=0.0002)(0.86 \pm 0.06 ; 0.79 \pm 0.05 ; 0.76$ \pm 0.08 ; respectively) whilst no significant differences were detected in RR in the MED group. No significant differences in REE were detected. Both groups showed a significant decrease in body weight at $t_{20}$ and $t_{40}$ compared to basal conditions (KEMEPHY basal $81.8 \pm 11.6 ; \mathrm{t}_{20} 77.8$ $\pm 11.4 ; \mathrm{t}_{40} 75 \pm 11.2$. MED basal $76.3 \pm 9.9$; $\mathrm{t} 2075.6 \pm 9.9 ; 71.7$ \pm 9.8 ) with the percentage changes in body weight being significantly greater for the KEMEPHY group. Both groups showed a significant decrease in body fat mass at $t_{20}$ and $t_{40}$ compared to basal conditions with the percentage changes in body fat mass being significantly greater for the KEMEPHY group $(\mathrm{P}=0.0135)$.

\section{Conclusions}

These preliminary data showed that whilst both diet protocols lead to a significant decrease in body weight, the reduction was significantly greater during KEMEPHY. The KEMEPHY diet also lead to a lowering of RR and increased fat oxidation at rest without any effect on REE. These findings suggest that one of the main weight loss mechanisms of KD might be attributed to an improvement in resting nutrient oxidation and interestingly this effect was long lasting, at least for up to 20 days following cessation of the ketogenic. Data on metabolic effects of KEMEPHY 3 months the ketogenic period will soon be available. 


\section{Author details}

${ }^{1}$ Biomedical Engineering Laboratory, Institute of Communication and

Computer Systems, National Technical University of Athens, Athens, Greece.

2 . ${ }^{3}$ Dept. of Sports and Exercise Science (DISMOT), University of Palermo,

Italy. ${ }^{4}$ Pharmaceutical and Chemistry and Technologies, University of Padova,

Italy. ${ }^{5}$ Tisanoreica Research Center, Lonigo, Vicenza, Italy.

Published: 1 June 2012

\section{References}

1. Volek JS, Sharman MJ: Cardiovascular and hormonal aspects of very-lowcarbohydrate ketogenic diets. Obes Res 2004, 12(Suppl 2):115S-23S.

2. Paoli A, Cenci L, Grimaldi KA: Effect of ketogenic Mediterranean diet with phytoextracts and low carbohydrates/high-protein meals on weight, cardiovascular risk factors, body composition and diet compliance in Italian council employees. Nutr J 2011, 10:112.

3. Paoli A, Cenci L, Fancelli M, Parmagnani A, Fratter A, Cucchi A, Bianco A: Ketogenic diet and phytoextracts: comparison of the efficacy of mediterranean, Zone and Tisanoreica diet on some health risk factors. Agro Food Ind Hi Tec 2010, 21:24-29.

4. Tagliabue A, Bertoli S, Trentani C, Borrelli P, Veggiotti P: Effects of the ketogenic diet on nutritional status, resting energy expenditure, and substrate oxidation in patients with medically refractory epilepsy: A 6month prospective observational study. Clin Nutr 2012, 31:246-249.

doi:10.1186/1753-6561-6-S3-P37

Cite this article as: Paoli et al:: Medium term effects of a ketogenic diet and a Mediterranean diet on resting energy expenditure and respiratory ratio. BMC Proceedings 2012 6(Suppl 3):P37.

\section{Submit your next manuscript to BioMed Central} and take full advantage of:

- Convenient online submission

- Thorough peer review

- No space constraints or color figure charges

- Immediate publication on acceptance

- Inclusion in PubMed, CAS, Scopus and Google Scholar

- Research which is freely available for redistribution

Submit your manuscript at www.biomedcentral.com/submit 